\title{
PERSEPSI PENGUNJUNG TERHADAP WISATA BAHARI DI PANTAI KLARA, PROVINSI LAMPUNG
}

\section{PERCEPTION OF VISITORS TO MARINE TOURISM AT KLARA BEACH, LAMPUNG PROVINCE}

\author{
Nurbaiti ${ }^{*}$, Sugeng Prayitno Harianto, Dian Iswandaru ${ }^{1}$, \\ Indra Gumay Febryano ${ }^{1,2}$
}

\author{
${ }^{1}$ Jurusan Kehutanan, Fakultas Pertanian, Universitas Lampung \\ 2 Manajemen Wilayah Pesisir dan Laut, Program Pascasarjana, Universitas Lampung \\ Jl. Prof. Dr. Soemantri Brojonegoro No 1, Bandar Lampung 35145 Indonesia \\ Email: nurbaitinubey87@gmail.com
}

\begin{abstract}
ABSTRAK
Persepsi pengunjung sangat penting dalam pengembangan wisata karena salah satu indikator yang dapat dijadikan acuan dalam pengelolaan wisata. Tujuan penelitian ini untuk mengetahui persepsi pengunjung terhadap pengembangan wisata bahari di Pantai Klara, Kabupaten Pesawaran, Provinsi Lampung. Pengumpulan data dilakukan dengan metode wawancara menggunakan kuesioner dan observasi. Data yang terkumpul kemudian dianalisis dengan attraction, accessibility, amenities, dan ancillary service dengan Skala Likert dan secara deskriptif kualitatif. Penilaian persepsi pengunjung terhadap atraksi, aksesibilitas, dan pelayanan tambahan tergolong kategori baik. Penilaian persepsi pengunjung terhadap fasilitas tergolong kategori netral, karena fasilitas yang terbatas. Pengelola diharapkan dapat melakukan pengembangan wisata secara optimal dengan menambahkan fasilitas yang dibutuhkan pengunjung, mengadakan evaluasi, dan penambahan pemandu wisata.
\end{abstract}

Kata kunci : pengembangan wisata, wisata bahari, persepsi, pengunjung

\begin{abstract}
Visitor perception is very important in tourism development because it is one of the indicators that can be used as a reference in tourism management. The purpose of this study was to determine the visitor's perception of the development of marine tourism in Klara Beach, Pesawaran Regency, Lampung Province. Data collection was carried out by the interview method using questionnaires and observation. The collected data were then analyzed using the attraction, accessibility, amenities, and ancillary services with a Likert Scale and a qualitative descriptive. The assessment of visitors' perceptions of attractions, accessibility, and additional services is in a good category. The assessment of visitors' perceptions of facilities is classified as a neutral category, due to limited facilities. Managers are expected to be able to develop tourism optimally by adding facilities needed by visitors, conducting evaluations, and adding tour guides.
\end{abstract}

Keywords : tourism development, marine tourism, perception, visitors

\section{PENDAHULUAN}

Indonesia dikenal sebagai negara kepulauan terbesar yang terbentang dari Sabang sampai Merauke (Wibowo et al., 2019). Selain itu, Indonesia menjadi salah satu destinasi pariwisata kelas dunia dan dikembangkan dalam kepariwisataan karena memiliki kekayaan alam dan budaya yang potensial (Rahayu, 2016). Perkembangan sektor pariwisata dicirikan oleh banyaknya kunjungan wisatawan yang dapat meningkatkan pemasukan sektor tersebut. Kunjungan wisatawan dipengaruhi oleh kepuasan wisatawan yang akan menentukan lama kunjungan wisatawan ke lokasi wisata tersebut (Marcelina et al., 2018). Industri pariwisata banyak memiliki hal yang cukup penting salah satunya layanan pariwisata atau jasa wisata (Effendi et al., 2015). Jasa wisata yang berasal dari keanekaragaman hayati, gejala alam, keindahan bentang alam, peninggalan sejarah, keunikan dan keaslian budaya tradisional yang dapat dimanfaatkan 
secara optimal untuk kesejahteraan masyarakat (Affandy et al., 2018), salah satunya potensi tersebut terdapat di wilayah kelautan atau pesisir.

Potensi kelautan atau pesisir dapat dimanfaatkan untuk meningkatkan perekonomian (Rahardian et al., 2020). Potensi wilayah pesisir dapat dikembangkan dalam bidang industri pariwisata sebagai penghasil devisa pertumbuhan ekonomi (Adriyani dan Husnita, 2012) yang banyak menyimpan potensi baik dari segi fisik, ekologi, maupun ekonomi (Ariftia et al., 2014). Potensi tersebut dapat berperan sebagai daya tarik untuk meningkatkan perekonomian kawasan pesisir (Wibowo et al., 2019). Wilayah pesisir juga sudah menjadi alternatif pariwisata yang sangat diminati oleh masyarakat karena menawarkan sesuatu yang berbeda, yaitu keindahan dan pendidikan lingkungan (Prasetyo et al., 2019). Pengelolaan wisata bahari yang baik dapat dilakukan dengan mengembangkan sarana dan fasilitas pendukung (Andriyani dan Husninta, 2012). Dukungan pihak pengelola pada suatu Pengelolaan wisata menjadi nilai tambah, yang dapat berfungsi membangun pengembangan wisata (Buli et al., 2018).

Pengembangan wisata yang terpenuhi akan memberikan pengaruh terhadap kepuasan pengunjung juga minat ingin datang kembali (Febryano dan Rusita, 2018). Persepsi pengunjung sangat penting dalam pengembangan wisata karena untuk diketahui sehingga dapat dijadikan sebagai langkah awal dalam pengembangan suatu objek wisata bahari (Prasetyo et al., 2019). Pemahaman terhadap persepsi tersebut merupakan salah satu indikator yang dapat dijadikan acuan dalam pengelolaan wisata (Lalika et al., 2019). Tujuan penelitian adalah mengetahui persepsi pengunjung terhadap pengembangan wisata bahari di Pantai Klara, Kabupaten Pesawaran, Lampung.

\section{METODE PENELITIAN}

Penelitian dilakukan di Pantai Klara, Kabupaten Pesawaran, Provinsi Lampung. Penelitian dilaksanakan selama tiga bulan yaitu pada bulan Juni-Agustus 2020. Alat yang digunakan dalam penelitian ini adalah kamera, clip board, alat tulis, dan kuesioner. Objek penelitian ini adalah pengunjung Pantai klara Kabupaten Pesawaran, Provinsi Lampung. peta lokasi penelitian ini dapat dilihat pada Gambar 1.

Pengumpulan data dilakukan dengan observasi dan wawancara. Pemilihan sampel responden pengelola menggunakan purposive sampling dan pengambilan sampel responden pengunjung dilakukan dengan random sampling dengan batasan umur $>17$ tahun dengan jumlah responden 98 orang. Menurut Sugiyono (2014); Denada, et al. (2020) Perhitungan populasi responden menggunakan Rumus Slovin.

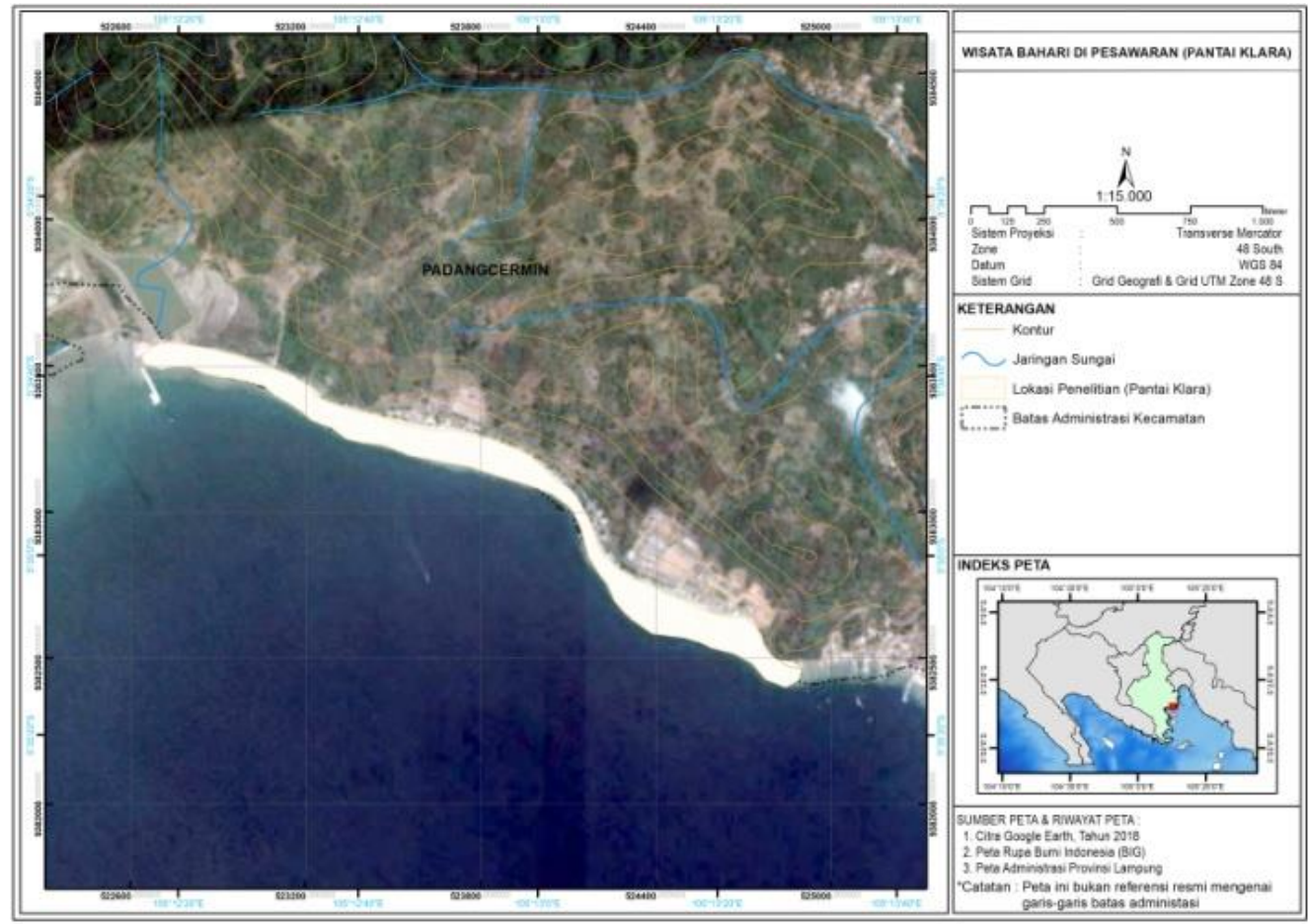

Gambar 1. Peta Lokasi Penelitian 


$$
\mathrm{n}=\frac{N}{1+N(e)^{2}}
$$

$$
\begin{aligned}
& \text { Jumlah responden Pantai Klara } \\
& \mathrm{n}=\frac{6.300}{1+6.300(0,1)^{2}}=98 \text { Responden }
\end{aligned}
$$

Keterangan : $\mathrm{N}=$ Ukuran sampel; $\mathrm{N}=$ Ukuran populasi; $\mathrm{E}=$ Persentase kelonggaran ketelitian kesalahan; Nilai e = 0,01 (10\%)

Kuesioner yang diberikan kepada pengunjung berupa pertanyaan-pertanyaan mengenai pengelolaan wisata di Pantai Klara Kabupaten Pesawaran Provinsi Lampung yang didasarkan pada aspek 4A yakni, attraction (atraksi) dengan 3 indikator pertanyaan meliputi, objek wisata, kondisi alam, dan partisipasi pengunjung; accessibility (aksesibilitas) dengan 4 indikator pertanyaan meliputi, ketersediaan jalan, kualitas dan kondisi jalan, transportasi umum, dan penunjuk jalan; amenities (fasilitas) dengan 4 indikator pertanyaan meliputi, toilet, gazebo, tempat ibadah, tempat penginapan, kantin dan restoran; dan ancillary service (pelayanan tambahan) dengan 4 indikator pertanyaan meliputi, keramahan pengelola, papan informasi, pemberian penjelasan, dan guide.

Penilaian indikator pada tiap aspek menggunakan acuan penilaian Skala Likert. Skala Likert yaitu untuk mengukur sikap dan pendapat individu atau sekelompok orang tentang fenomena sosial yang diukur (Sugiyono, 2007; Sugandi, et al., 2015). Penilaian tersebut menggunakan bobot penilaian saat di lapangan dapat dilihat pada Tabel 1. Data yang sudah didapatkan kemudian dianalisis dengan deskriptif kualitatif.

Rumus perhitungan yang digunakan dalam analisis Skala Likert menggunakan Microsoft Excel yaitu:

Perhitungan scoring Skala Likert

Perhitungan scoring Skala Likert dapat dihitung menggunakan rumus sebagai berikut:

$$
\begin{aligned}
\mathrm{NL}= & \sum\left(n_{1} \times 1\right)+\left(n_{2} \times 2\right)+\left(n_{3} \times 3\right)+ \\
& \left(n_{4} \times 4\right)+\left(n_{5} \times 5\right)
\end{aligned}
$$

Keterangan: $\mathrm{NL}=$ nilai scoring Skala Likert; $\mathrm{n}$ = jumlah jawaban score

Perhitungan rata-rata tiap aspek pertanyaan Perhitungan rata-rata tiap aspek pertanyaanpertanyaan yang ada Skala Likert dapat dihitung menggunakan rumus sebagai berikut:

$$
\mathrm{Q}=\mathrm{NL} / \mathrm{X}
$$

Keterangan: $\mathrm{Q}$ = rata-rata aspek pertanyaan ke-i; $\mathrm{NL}=$ nilai scoring Skala Likert; $\mathrm{x}=$ jumlah sampel responden

Perhitungan nilai akhir tiap aspek

Perhitungan nilai akhir tiap aspek pada Skala Likert dapat dihitung menggunakan rumus sebagai berikut

$$
\mathrm{NA}=\frac{\mathrm{Q} 1+\mathrm{Q} 2+\mathrm{Q} 3+\cdots+\mathrm{Qp}}{\mathrm{p}}
$$

Keterangan: NA = nilai akhir; $\mathrm{Qp}=$ rata-rata tiap aspek pertanyaan; $p=$ jumlah seluruh pertanyaan

Tabel 1. Bobot Nilai Skala Likert

\begin{tabular}{lc}
\hline \multicolumn{1}{c}{ Pernyataan } & Nilai \\
\hline Sangat Tidak Setuju & 1 \\
Tidak Setuju & 2 \\
Cukup Setuju & 3 \\
Setuju & 4 \\
Sangat Setuju & 5
\end{tabular}

Sumber : Sugiyono (2014); Denada, et al. (2020)

\section{HASIL DAN PEMBAHASAN}

Pantai Klara termasuk dalam bagian Wilayah pesisir Teluk Lampung dan secara administratif terletak di Desa Ketapang, Kecamatan Padang Cermin, Kabupaten Pesawaran, Provinsi Lampung. Kabupaten yang ada di Provinsi Lampung yang memiliki banyak potensi alam yang menarik untuk dijadikan obyek pariwisata. Pantai Klara sepanjang 1,25 Km ini berbatasan langsung dengan jalan raya Teluk Ratai sehingga pantai ini dapat terlihat secara langsung bagi pengendara kendaraan yang melintas dari jalan tersebut (Ginting, 2013). Secara geografis lokasi penelitian terletak pada 5038'47" LS sampai 507'6" LS dan 105014' BT sampai 105004' BT (Sepriyansyah et al., 2016).

Nama Klara ini diambil dari kependekan Kelapa Rapat. Lokasi pantai ini sangat banyak pohon kelapa yang jaraknya berdekatan sehingga membentuk kanopi atau peneduh bibir sekitar pantai. Lokasi tersebut sekitar $22 \mathrm{Km}$ tepatnya berada di Teluk Lampung menghadap bagian Barat Daya. Ombaknya yang tidak terlalu besar dapat memberikan rasa aman dan nyaman bagi pengunjung dan juga pasir yang berwarna putih mendominasi pantai ini merupakan 
salah satu panorama alam yang sangat menakjubkan (Dinas Pariwisata dan Ekonomi Kreatif Provinsi Lampung, 2020). Objek daya tarik wisata di Pantai Klara sudah terpenuhi dengan baik karena dapat dilihat dari sekitar pantai ini dipenuhi pepohonan sepanjang pantai sehingga dapat menarik perhatian pengunjung.

Jarak lokasi pantai ini dengan kota Bandar Lampung tidak begitu jauh. Pengunjung yang dapat menggunakan kendaraan roda dua atau roda empat hanya memakan waktu satu jam. Pengelolaan Pantai Klara dapat dilaksanakan oleh Primer Koperasi Pangkalan (Primkopal) TNI AL Panjang sejak tahun 2005. Pihak Primkopal memang membuka kawasan Pantai Klara untuk rekreasi masyarakat sebagai salah satu sumber pemasukan Primkopal. Secara keseluruhan luas tapa $\mathrm{k}$ adalah 14,7 ha (Ginting, 2013). Pantai ini menjadi tempat wisata yang sering dikunjungi oleh wisatawan karena kondisi alam dan lingkungan yang nyaman dan sejuk sehingga menimbulkan minta wisatawan kembali datang.

\section{Persepsi Pengunjung Terhadap Pengembangan wisata Bahari Atraksi}

Persepsi pengunjung terhadap atraksi dapat dilihat pada Gambar 2. Atraksi dapat juga mencakup keunikan dan daya tarik meliputi alam, budaya, maupun buatan (Suwena dan Widyatmaja, 2010: Khotimah et al., 2017).

Persepsi pengunjung terhadap atraksi dengan nilai rata-rata tertinggi pada kondisi alam $(4,33)$. Kondisi alam meliputi keindahan alam dan keanekaragaman hayati. Pengunjung menilai bahwa lokasi Pantai Klara memiliki pasir yang putih, air yang bersih, ombaknya tidak besar, dan suasana sejuk yang disebabkan banyaknya pepohonan yang berada sekitar pantai. Beberapa jenis pohon yang dapat ditemukan di pantai ini antara lain ketapang (Terminalia catappa), waru (Hibiscus tiliaceus), cemara laut (Casuarina equisetifolia) dan kelapa (Cocos nucifera). Selain itu pengunjung menilai dengan adanya pepohonan terlihat lebih indah dan asri, sehingga menciptakan kondisi yang nyaman.

Kesejukan pepohonan dapat menciptakan rasa nyaman dan betah (Agapa dan Widyastuty, 2014; Maharani, 2014; Wanti et al., 2014; Dewi et al., 2016; dan Sulistyana et al., 2017; Sari, et al., 2020) dan keindahan salah satu tujuan pengunjung menghilangkan kejenuhan (Putri, et al., 2020; Sari, et al., 2020). keanekaragaman hayati yang dapat memberikan kontribusi untuk pengembangan kawasan wisata, sehingga kepuasan pengunjung terpenuhi (Murvianti dan Arida, 2015; Affandy et al., 2016; Firawan dan Suryawan, 2016; Walimbo et al., 2017; dan Pratiwi, 2019).

Atraksi pendukung tergolong dalam kategori baik dengan nilai rata-rata 4,31, karena lokasi tersebut memiliki objek yang menarik perhatian pengunjung seperti jembatan dermaga dan ayunan. Partisipasi pengunjung tergolong dalam kategori netral dengan nilai rata-rata terkecil yaitu 3,95. Pemahaman pengunjung yang terbatas dalam pengembangan wisata dapat dijadikan acuan untuk pengelolaan wisata yang lebih baik (Khotimah et al., 2017; Denada, et al., 2020). Namun berdasarkan penilaian tiga indikator tersebut menunjukkan persepsi pengunjung terhadap atraksi tergolong baik.

\section{Aksesibilitas}

Persepsi pengunjung terhadap aksesibilitas dapat dilihat pada Gambar 3. Aksesibilitas salah satu sarana yang menghubungkan pengunjung dengan objek wisata baik berupa alat transportasi atau akses informasi (Abdulhaji dan Yusuf, 2016).

Persepsi pengunjung terhadap aksesibilitas menunjukkan rata-rata nilai tertinggi $(7,33)$ untuk petunjuk jalan dengan kategori baik. Petunjuk jalan yang tersedia tidak terlalu besar, namun kondisinya baik dengan tata letak yang strategis sehingga mudah untuk dilihat. Menurut Hadiwijoyo (2012); Setyanto dan Pangestuti (2019), informasi melalui petunjuk jalan memberikan kemudahan pada pengunjung untuk menuju lokasi wisata.

Ketersediaan jalan tergolong dalam kategori baik dengan nilai rata-rata 4,33, karena jalan yang tersedia dapat memudahkan akses menuju lokasi. selain itu, waktu yang ditempuh menjadi lebih singkat. Kualitas dan kondisi jalan yang tidak terlalu lebar dan kualitas jalan dengan aspal tipis, sehingga memilki nilai rata-rata $(3,92)$ tergolong dalam kategori netral. Menurut Soekadijo (2010); Setyanto (2019), aksesibilitas jalan menuju lokasi harus mudah dicapai dan kualitas kondisi jalan yang baik dapat mempermudah sampai ke tempat objek wisata.

Transportasi umum tergolong dalam kategori netral dengan nilai rata-rata terkecil 3,32. Hal ini disebabkan belum ada transportasi umum yang khusus mengantarkan pengunjung menuju lokasi, 
sehingga pengunjung lebih memilih untuk menggunakan kendaraan pribadi.

Penilaian persepsi pengunjung terhadap aksesibilitas didasarkan empat indikator tersebut tergolong baik. Menurut Febryano dan Rusita (2018); Rusita dan Febryano (2019), aksesibilitas yang kurang layak akan mengganggu kegiatan pariwisata. Aksesibilitas salah satu aspek terpenting, terpenuhinya aksesibilitas yang memadai dapat memberikan kemudahan bagi pengunjung untuk mendatangi lokasi tersebut (Khotimah et al., 2017; Denada, et al., 2020).

\section{Fasilitas}

Persepsi pengunjung terhadap fasilitas dapat dilihat pada Gambar 4. Fasilitas salah satu prasarana untuk memenuhi kebutuhan akomodasi, penyediaan makanan dan minuman, serta memberikan pengaruh apabila kurangnya fasilitas menjadikan wisatawan menghindari destinasi tersebut (Khotimah et al., 2017).

Persepsi pengunjung terhadap fasilitas dengan nilai rata-rata tertinggi $(4,07)$ tergolong dalam kategori baik. Hal ini dikarenakan menurut pengunjung bangunan gazebo sebagai tempat istirahat. Ketersediaan toilet tergolong dalam kategori netral dengan nilai rata-rata 3,92. Tempat ibadah tergolong dalam kategori netral dengan nilai rata-rata 3,7. Pengunjung menilai bangunan tempat ibadah kurang luas yang menyebabkan pengunjung harus mengantri saat ingin shalat. Namun disisi lain, kondisi bangunan tempat ibadah yang terawat sehingga terkesan baik dari pengunjung.

Kantin dan restoran menunjukkan nilai rata-rata 3,66 tergolong dengan kategori netral. Meskipun demikian, pengunjung

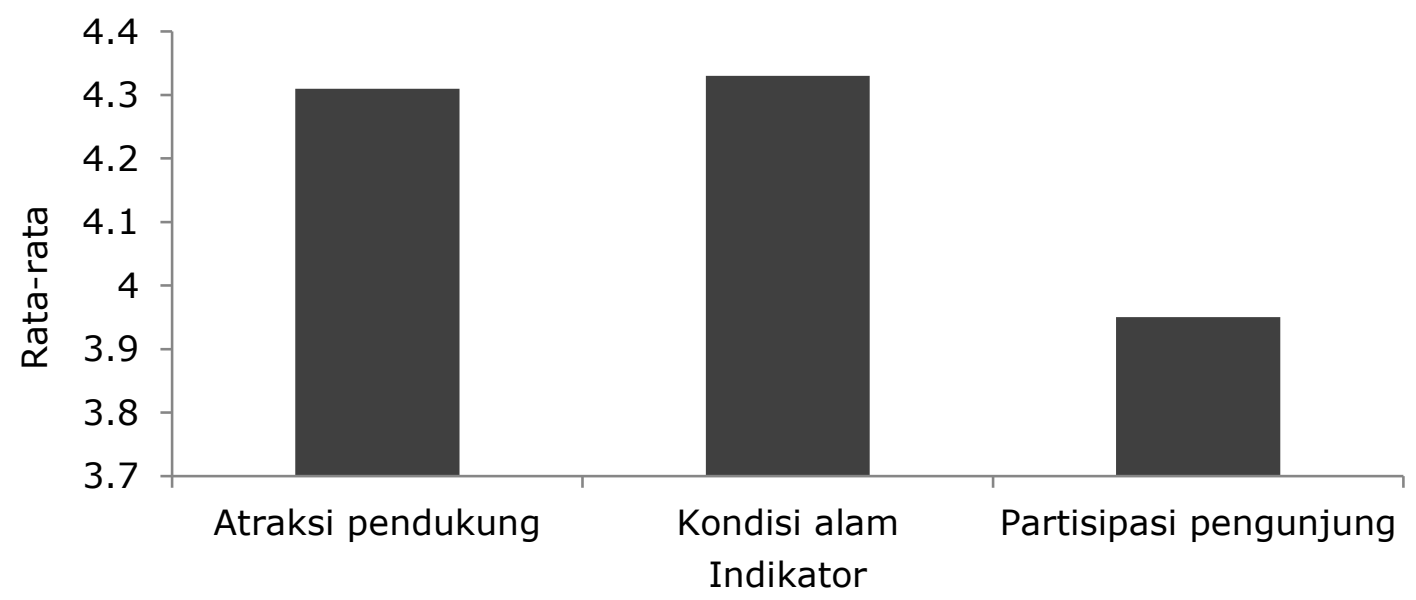

Gambar 2. Persepsi Pengunjung Terhadap Atraksi di Pantai Klara

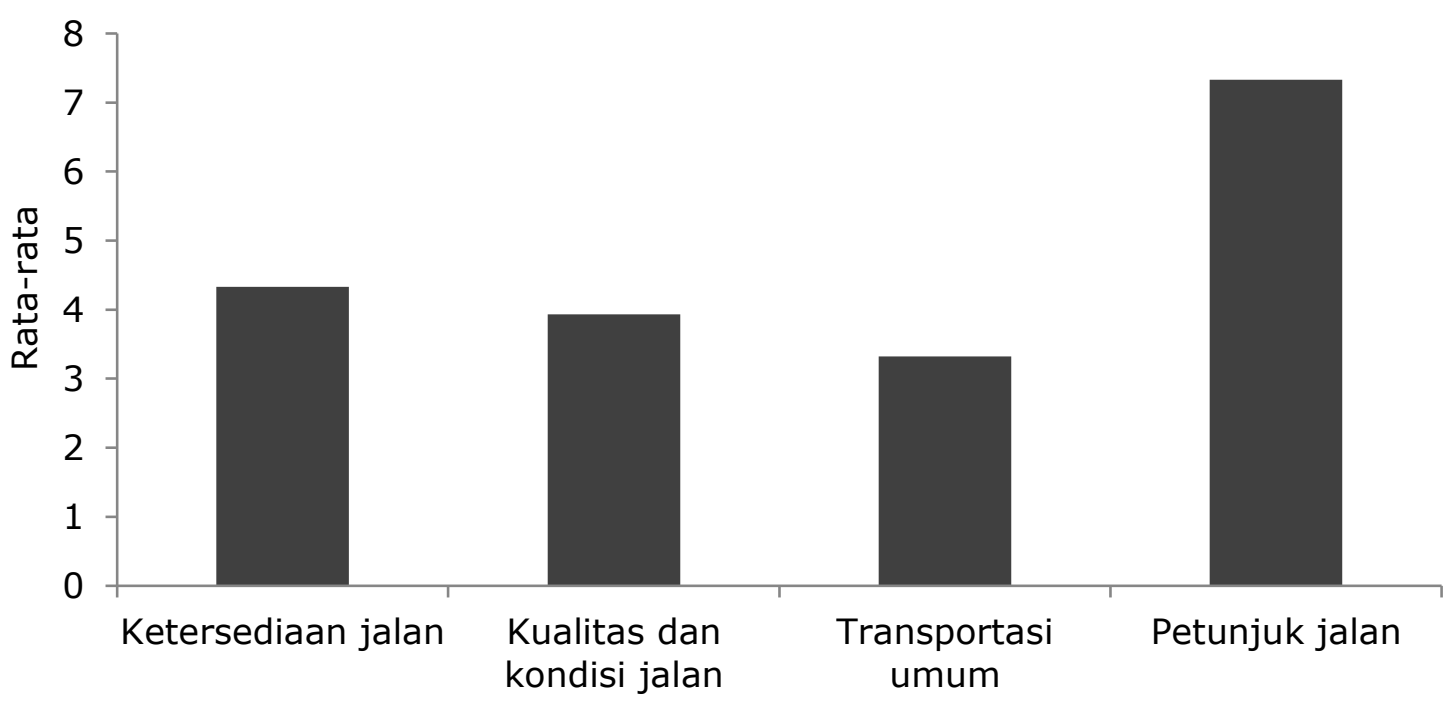

Indikator

Gambar 3. Persepsi Pengunjung Terhadap Aksesibilitas di Pantai Klara 
menilai harga produk yang dijual relatif murah. Hal ini, dapat menarik minat pengunjung datang kembali sehingga kantin dan restoran salah satu indikator penting dalam fasilitas dapat terpenuhi. Tempat penginapan memiliki rata-rata terkecil 3,49 tergolong dengan kategori netral, karena pihak pengelola belum menyediakan tempat penginapan untuk pengunjung yang datang.

Penilaian persepsi pengunjung terhadap fasilitas didasarkan empat indikator tersebut tergolong netral. Fasilitas salah satu hal penting yang disediakan pengelola agar dapat menarik perhatian pengunjung datang kembali (Sihotang et al., 2014; Ahmad et al., 2020). Pengembangan wisata ditujukan untuk konservasi dengan destinasi wisata (Febryano et al., 2014). Fasilitas yang memadai akan berpengaruh dengan jumlah pengunjung yang datang, karena pengunjung merasa puas dengan fasilitas yang diberikan (Marcelina, et al., 2018). Selain itu, pengunjung yang merasa puas dengan fasilitas yang terpenuhi akan cenderung datang kembali (Kalebos, 2016; Marcelina et al., 2018).

\section{Pelayanan Tambahan}

Persepsi pengunjung terhadap pelayanan tambahan dapat dilihat pada Gambar 5. Menurut Khotimah et al. (2017) pelayanan tambahan lebih kepada ketersediaan sarana dan fasilitas umum yang digunakan oleh pengunjung yang juga mendukung kegiatan wisata seperti bank, ATM, telekomunikasi, rumah sakit dan sebagainya. Keberadaan berbagai organisasi atau stakeholder untuk memfasilitasi dan mendorong pengembangan serta pemasaran kepariwisataan destinasi bersangkutan.

$$
\text { Persepsi pengunjung terhadap }
$$

pelayanan tambahan (ancillary service) menunjukkan keramahan pengelola memiliki nilai rata-rata tertinggi 4,43 tergolong dalam kategori baik. Pengunjung beranggapan bahwa sebagian pengelola bersikap peka kepada pengunjung saat membutuhkan sesuatu. Selain itu, sikap antusias yang ditujukan pengelola menyebabkan pengunjung tidak sungkan dalam meminta bantuan terutama dalam penanganan apabila terjadi kecelakaan saat berada di lokasi pantai ini, seperti tersenggat bulu babi. Menurut Iswandaru, et al. (2016); Sari., et al. (2020) komunikasi menimbulkan interaksi antara pengelola dengan pengunjung.

Papan informasi dan pemberian penjelasan tergolong dengan kategori baik memiliki nilai rata-rata 4,14 dan 4,35. Ketersediaan guide memiliki nilai rata-rata terkecil 3,64 tergolong dalam kategori netral, karena seharusnya pihak pengelola menyediakan pemandu wisata lebih banyak agar intensitas pengunjung dan pengelola sebanding.

Penilaian persepsi pengunjung terhadap pelayanan tambahan tergolong dalam kategori baik, karena pengunjung menilai pelayanan tambahan yang disediakan pengelola sudah terpenuhi. Pengembangan pengelolaan dan kelembagaan sangat diperlukan untuk mendukung berlangsungnya kegiatan wisata (Sunaryo, 2013) serta memberikan kepuasan kepada pengunjung (Teguh et al., 2010), untuk dapat meningkatkan intensitas kunjungan dan daya tarik (Juwita, 2015; Denada, et al., 2020).

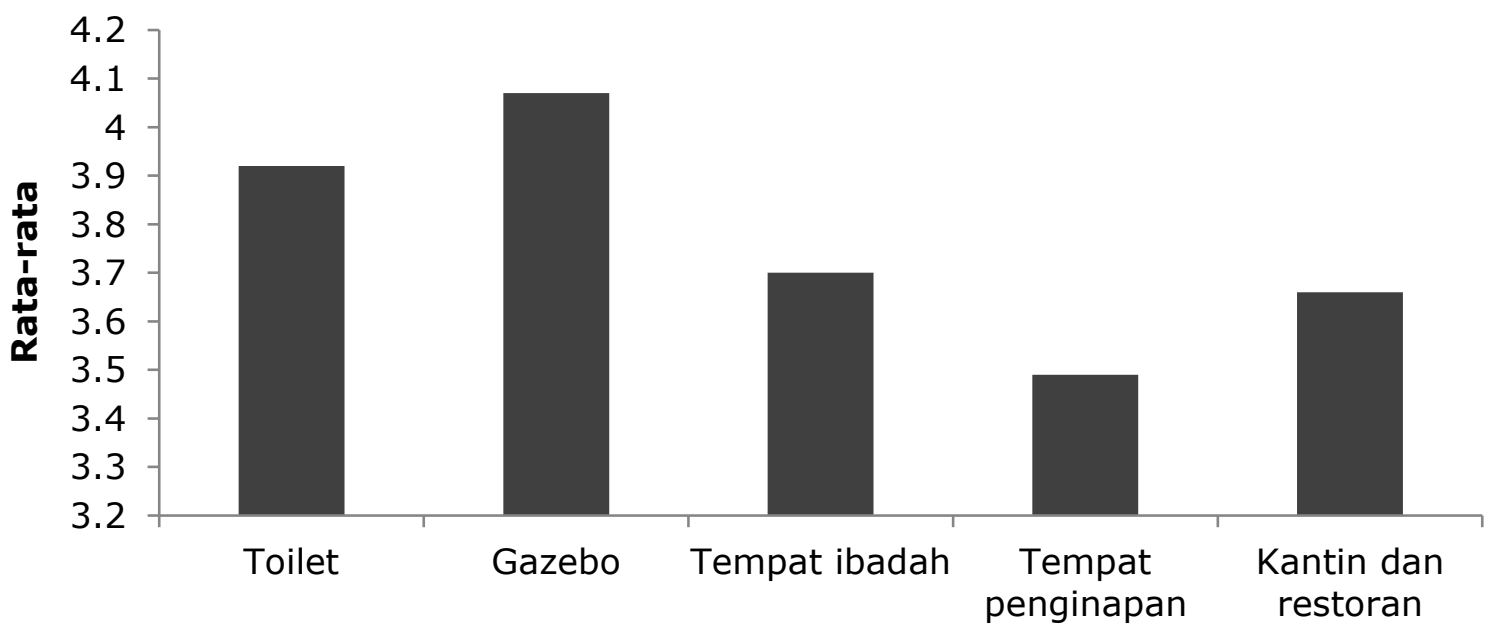

Indikator

Gambar 4. Persepsi Pengunjung Terhadap Fasilitas di Pantai Klara 


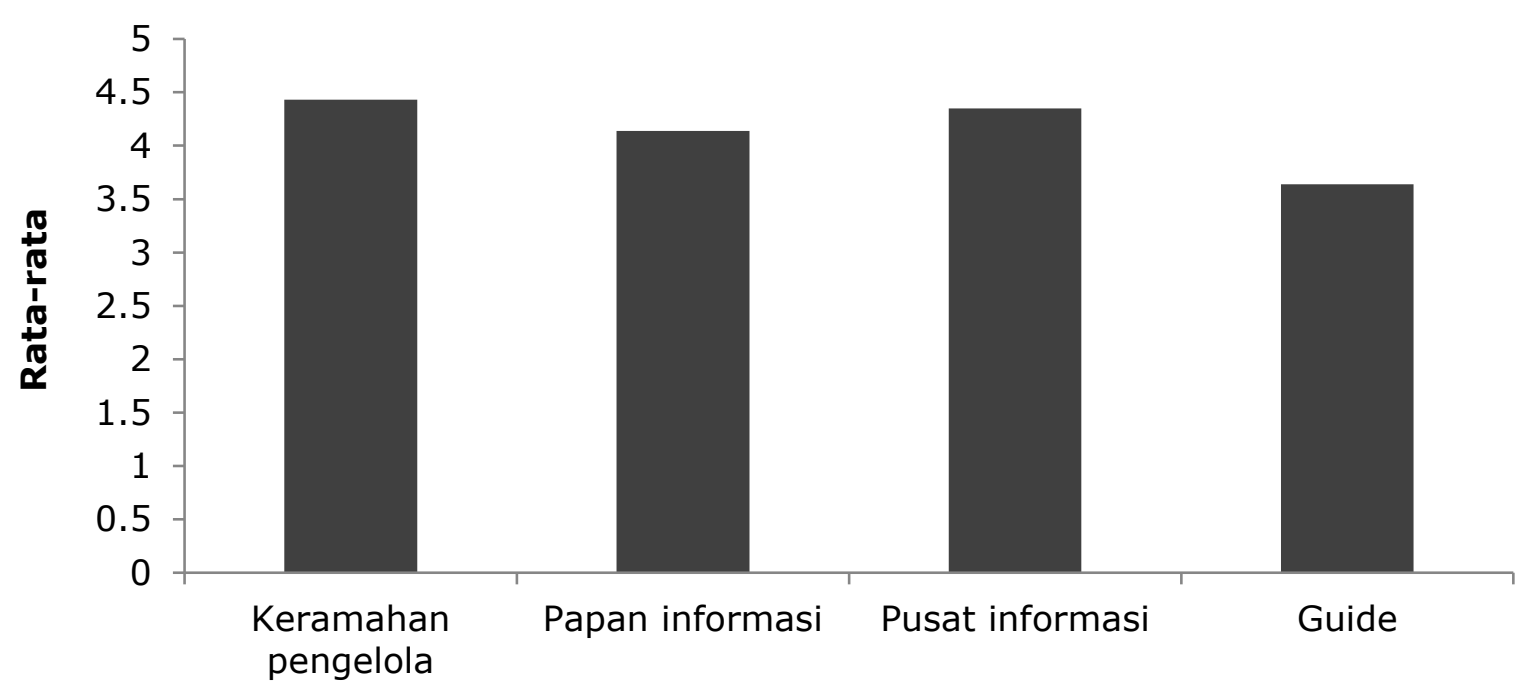

\section{Indikator}

Gambar 5. Persepsi Pengunjung Terhadap Pelayanan Tambahan (Ancillary Service) di Pantai Klara

\section{KESIMPULAN}

Penilaian persepsi pengunjung terhadap atraksi, aksesibilitas, dan pelayanan tambahan tergolong kategori baik. Namun di sisi lain, penilaian terhadap fasilitas tergolong netral, sehingga penilaian pengunjung terhadap pengelola diharapkan dapat melakukan penambahan fasilitas-fasilitas untuk dapat memenuhi kebutuhan pengunjung dan meningkatkan minat pengunjung untuk datang kembali.

\section{REFERENSI}

Abdulhaji, S. \& Yusuf, I.S.H. 2016. Pengaruh atraksi, aksesibilitas, dan fasilitas terhadap citra objek wisata Danau Tolire Besar di Kota Ternate. Jurnal Penelitian Humano, 7(2):134-138.

Affandy, B., Setiawan, A. \& Duryat. 2018. Potensi wisata alam di Pematang Tanggang Desa Negeri Kecamatan Kelumbayan Kabupaten Tanggamus. Jurnal Sylva Lestari, 4(1):41-50

Agapa, F.A. \& Widyastuty, A.A.S.A. 2014. Penataan kawasan Pulau Mansinam sebagai obyek wisata alam di Teluk Doreri Kabupaten Manokwari Propinsi Papua Barat. Jurnal Teknik Waktu, 12(1):8-16.

Ahmad, F., Winarno, G.D., Darmawan, A., Wulandari, C., Harianto, S.P., \& Febryano, I.G. 2020. Persepsi pengunjung dalam pengembangan ekowisata di Wana Wisata Tanjung
Harapan, Lampung. Jurnal Hutan Tropis, 9(3):1-8.

Andriyani, I. \& Husnita, L. 2012. Perubahan sosial ekonomi masyarakat pasca pengembangan wisata bahari di Kepulauan Sikakap, Kabupaten Mentawai. Jurnal IImu Sosial Mamangan, 1(2): 95-101.

Ariftia, R.I., Qurniati. R. \& Herwanti, S. 2014. Nilai ekonomi total hutan mangrove Desa Margasari Kecamatan Labuhan Maringgai Kabupaten Lampung Timur. Jurnal Sylva Lestari, 2(3):19-28.

Buli, W., Bakri, S. \& Febryano, I.G. 2018. Kelembagaan pertambangan batu bara di hutan rakyat. Jurnal Sylva Lestari, 6(3):81-90.

Denada, A.N.I., Winarno, G.D., Iswandaru, D. \& Fitriana, Y.R. 2020. Analisis persepsi pengunjung dalam pengelolaan lebah madu untuk mendukung kegiatan ekowisata di Desa Kecapi, Kalianda, Lampung Selatan. Jurnal Belantara, 3(2):153-162.

Dewi, R.S., Widodo, P. \& Budiarti, L.N. 2016. Pengaruh unsur alam terhadap minat berkunjung kembali di Mal. Jurnal Visual Art dan Design, 8(2):94-107.

Dinas Pariwisata dan Ekonomi Kreatif Provinsi Lampung. $2020 . \quad$ Website: https://dinaspariwisata.lampungprov.go .id/halaman/detail/pantai-klara.

Effendi, A., Bakri, S. \& Rusita. 2015. Nilaii ekonomi jasa wisata Pulau Tangkil Provinsi Lampung dengan pendekatan metode biaya perjalanan. Jurnal Sylva Lestari, 3(3):71-84. 
Febryano, I.G., Suharjito, D., Darusman, D., Kusmana, C. \& Hidayat A. 2014. The roles and suistainability of local institutions of mangrove management in Pahawang Island. Jurnal Management Hutan Tropika, 20(2):69-76.

Febryano. I.G. \& Rusita. 2018. Persepsi wisatawan dalam pengembangan wisata pendidikan berbasis konservasi Gajah Sumatera (Elephas Maximus Sumatranus). Jurnal Pengelolaan Sumberdaya Alam dan Lingkungan, 8(3):376-382.

Firawan, I.G.N.F. \& Suryawan. 2016. Potensi daya tarik wisata air terjun nungnung sebagai daya tarik wisata alam. Jurnal Destinasi Pariwisata, 4(2):92-95.

Ginting, N.A.N. 2013. Perencanaan lanskap pesisir Pantai Klara sebagai kawasan rekreasi di Kecamatan Padang Cermin Kabupaten Pesawaran Lampung. Bogor: Institusi Pertanian Bogor. 38 hal.

Hadiwijoyo, S.S. 2012. Perencanaan pariwisata perdesaan berbasis masyarakat (sebuah pendekatan konsep). Yogyakarta: Graha Ilmu. 111 hal.

Hardian, D., Febryano., I.G., Supono, Damai, A.A. \& Winarno, G.D. 2020. Pelarangan cantrang: Strategii pengembangan pengembangan keberlanjutan sumberdaya ikan di Teluk Lampung. Journal of Tropical Marine Science, 3(1):21-27.

Iswandaru, D., Kusumandari, A. \& Fandeli, C. 2016. Studi implementasi standar sistem manajemen lingkungan (ISO 14001: 2004) dalam pengelolaan wisata alam di Taman Nasional Bromo Tengger Semeru (studi kasus pelaksanaan sertifikasi dalam pengelolaan wisata alam). Jurnal Hutan Pulau-Pulau Kecil, 1(2):117-127.

Juwita, I.A.E.R. 2015. Strategi pemasaran Museum Wayang kekayon Yogyakarta dalam meningkatkan jumlah pengunjung. Jurnal Tata Kelola Seni, $1(1): 60-74$.

Kalebos, F. 2016. Faktor-faktor yang mempengaruhi kepuasan wisatawan yang berkunjung ke Daerah Wisata Kepulauan. Jurnal Riset Bisnis dan Manajemen, 4(3):489-502.

Khotimah, K., Wilopo, \& Hakim, L. 2017. Strategi Pengembangan destinasi pariwisata budaya (studi kasus pada Kawasan Situs Trowulan sebagai pariwisata budaya unggulan dii
Kabupaten Mojokerto). Jurnal Administrasi Bisnis, 41(1):56-65.

Lalika, H.B., Herwanti, S., Febryano, I. G. \& Winarno, G.D. 2019. Persepsi pengunjung terhadap pengembangan ekowisata di Kebun Raya Liwa. Jurnal Belantara, 3(1):25-31.

Maharani, D. 2014. Makna pariwisata Pulau Kemaro menurut pengunjung dan perilaku komunikasinya. Jurnal Kajian Komunikasi, 2(1):73-83.

Marcelina, S.D., Febryano, I.G., Setiawan, A. \& Yuwono. S.B. 2018. Persepsi wisatawan terhadap fasilitas wisata di Pusat Latihan Gajah Taman Nasional Way Kambas. Jurnal Belantara, $1(2): 45-53$.

Murvianti, D.S. \& Arida, I.N. S. 2015. Potensi pantai perancak sebagai daya tarik wisata Desa Tibubeneng Kuta Utara Badung. Jurnal Destinasi Pariwisata, $3(2): 12-25$.

Prasetyo, D., Darmawan, A. \& Dewi, B.S. 2019. Persepsi wisatawan dan individu kunci tentang pengelolaan ekowisata di Lampung Mangrove Center. Jurnal Sylva Lestari, 7(1):22-29.

Pratiwi, N.K.O. 2019. Analisis SWOT untuk meningkatkan kunjungan wisata di objek wisata Goa Gajah Desa Bedulu, Kecamatan Blahbatuh, Kabupaten Gianyar. Jurnal Pendidikan Ekonomi Undiksha, 11(1):95-105.

Putri, S.A.T., Suastika, M. \& Samsudi. 2020. Penerapan konsep sapta pesona pada pengembangan Taman Budaya Jawa Tengah sebagai destinasi wisata di Surakarta. Jurnal IImiah Mahasiswa Arsitektur, 3(1):210-219.

Rahayu, E. 2016. Potensi dan strategi pengembangan pariwisata minat khusus Gua Paesan di Desa Tambakromo Kecamatan Ponjong Kabupaten Gunung Kidul. E-Jurnal Geo Educasia, 1(4):113.

Rusita, Febryano, I.G., Yuwono, S.B. \& Banuwa, I.S. 2019. Potensi hutan rawa air tawar sebagai alternatif ekowisata berbasis konservasi Gajah Sumatera (Elephas Maximus Sumatranus). Jurnal Pengelolaan Sumberdaya Alam dan Lingkungan, 9(2):498-506.

Sari, N.N., Winarno, G.D., Harianto, S.P. \& Fitriana, Y.R. 2020. Analisis potensi dan persepsi wisatawan dalam implementasi sapta pesona di objek wisata Belerang Simpur Desa Kecapi. Jurnal Belantara, 3(2): 163-172. 
Sepriansyah, P., Suwarni, N. \& Kurnia, R. 2016. Deskripsi objek wisata Kelapa Rapet Kabupaten Pesawaran. Jurnal Penelitian Geografi, 4(2):1-11.

Setyanto, I. \& Pangestuti, E. 2019. Pengaruh komponen destinasi wisata (4A) terhadap kepuasan pengunjung Pantai Gemah Tulungagung.Jurnal Administrasi Bisnis, 72(1):157-167.

Sihotang, J.S., Wulandari, C. \& Herwanti, S. 2014. Nilai objek wisata air terjun Way Lalaan Provinsi Lampung dengan metode biaya perjalanan (travel cost). Jurnal Sylva Lestari, 2(3):11-18.

Sugandi, U. Hernawan, D. \& Ratnamulyani, I.A. 2015. Hubungan pengawasan dengan efektivitas kerja pegawai. Jurnal Governansi, 1(1):35-43.

Sugiyono. 2007. Metode penelitian kuantitatif Kualitatif R\&D. Bandung: Alfabeta. 464 hal.

Sugiyono. 2014. Metode penelitian kuantitatif Kualitatif R \& D. Bandung: Alfabeta. 372 hal.

Sulistyana, M.I.C.D., Yuwono, S.B. \& Rusita. 2017. Kenyaman hutan kota Linara berbasis kerapatan vegetasi, iklim, mikro dan persepsi masyarakat di Kota Metro. Jurnal Sylva Lestari, 5(2):78-87.

Sunaryo, B. 2013. Kebijakan pembangunan destinasi pariwisata konsep dan aplikasinya di Indonesia. yogyakarta: Gava Media. 159 hal.

Suwena, I.K. \& Widyatmaja, I.G.N. 2010. Pengetahuan Dasar Ilmu Pariwisata. Bali: Udayana University Press. 252 hal.

Teguh, I.G., Rachmawati, E. \& Masy'ud, B. 2010. Studi tentang motivasi dan persepsi pengunjung terhadap pengelolaan pemanfaatan satwa sebagai objek wisata di satwa Punti Kayu Palembang Sumatera Selatan. Jurnal Media Konservasi, 15(3):131138.

Walimbo, R., Wulandari, C. \& Rusita. 2017. Studi daya dukung ekowisata Air Terjun Wiyono di Taman Hutan Raya Wan Abdul Rachman Provinsi Lampung, Jurnal Sylva Lestari, 5(1):47-60.

Wanti, L.W., Syaukat, Y. \& Juanda, B. 2014. Analisis nilai ekonomi wisata Kebun Kina Bukit Unggul Kabupaten Bandung. Jurnal Ekonomi Pertanian, Sumberdaya dan Lingkungan, 1(2):44-55.

Wibowo, T.A., Kaskoyo, H. \& Damai, A.A. 2019. Pengembangan wisata pantai mutun terhadap dampak fisik, sosial dan ekonomi masyarakat Desa Sukajaya Lempasing, Kabupaten Pesawaran, Lampung. Jurnal Pengembangan Kota, 7(1):83-90. 